1 Short title: Electrical responses in poplar

2 Corresponding author: Erwan Tinturier,

3 Université Clermont-Auvergne,

4 UMR 547-PIAF

51 impasse Amélie Murat

663178 Aubière, France

7 e-mail : e.tinturie@gmail.com

8

9

10 


\section{Stem bending generates electrical response in poplar}

12 Erwan Tinturier, Éric Badel, Nathalie Leblanc-Fournier, Jean-Louis Julien

One sentence summary: Poplar stem bending induces an electrical response with high speed and strong decrement.

Author contributions: JL.J conceived the original screening and research plans. E.B and E.T designed the experiments. Experimental work carried out and interpreted by E.T. First draft of the article wrote by E.T. All authors contributed to the writing of the article.

The author responsible for distribution of materials integral to the findings presented in this article in accordance with the policy described in the Instructions for Authors (www.plantphysiol.org) is: Erwan Tinturier (e.tinturie@gmail.com).

This work was funded by the I-SITE CAP 20-25 (ANR grant 16-IDEX-0001) Emergence 2019 from the University of Clermont-Auvergne, France.

Corresponding author: e.tinturie@gmail.com 


\section{Abstract}

Under natural conditions, plants experience external mechanical stresses such as wind and touch that impact their growth. A remarkable feature of this mechanically induced growth response is that it may occur at distance from the stimulation site, suggesting the existence of a signal propagating through the plant. In this study, we investigated the electrical response of poplar trees to a transient controlled bending stimulation of the stem that mimics the mechanical effect of wind. Stem bending was found to cause an electrical response that we called 'gradual' potential, similar in shape to an action potential. However, this signal distinguished from the well-known plant action potential by its propagation up to $20 \mathrm{~cm}$ along the stem and its strong dumping in velocity and amplitude. Two hypotheses regarding the mode of propagation of the 'gradual' potential are discussed.

\section{Key words:}

Trees, bending, electrical signaling, 'gradual' potential, decrement

\section{Introduction}

Plants perceive mechanical disturbances from their environment and adjust their growth according to a process called thigmomorphogenesis (Jaffe, 1973). In natural conditions, trees experience wind every day, applying recurrent force loadings that lead to mechanical strain of stem and branches. As a physiological response, trees in windy environments show a low primary growth and an increase of their diameter (Telewski, 2006). The responses to mechanical disturbances can be local or remote. As shown by Coutand et al. (2000), bending of a tomato stem leads to a rapid cessation of primary growth away from the stimulated area. Although, this rapid response has not been confirmed in poplar after a single basal flexion of the stem (Tixier et al., 2014), a slowdown in primary growth was observed following daily repeated flexions for weeks (Niez et al., 2019). These observations suggest the ability of the plants to transport mechanically-induced information over a long distance.

Several long-distance signaling ways can be considered from the literature essentially studied after wounding stimuli: chemical signaling (Choi et al., 2016), hydraulic pulse (Malone, 1993; Lopez et al., 2014) and electrical signaling (Mousavi et al., 2013; Hedrich et al., 2016). Although these pathways are generally studied separately, they are likely to interact (Farmer et al., 2014; Van Bel et al., 2014). The electrical signaling hypothesis has not yet been studied in case of non-wounding mechanical stimulations such as organ bending triggered by wind. 
In plants, two types of electrical signals were described: the action potential (AP) and the slow wave $(\mathrm{SW})$ or variation potential. The $\mathrm{SW}$ is characteristic of a response to a solicitation producing wounds. It is consisted of a rapid depolarization phase followed by a short plateau step where the transmembrane potential remains stable, and finally a repolarization step lasting variably from 1 to 45 minutes. Its propagation speed is of the order of mm.s ${ }^{-1}$ (Sambeek and Pickard, 1976; Roblin and Bonnemain, 1985; Julien et al., 1991). The SW is positively correlated with stimulus intensity and its amplitude decreases with increasing distance from the stimulation site (Stahlberg et al., 2005). Several studies reported the SW involvement in the activation of defense mechanisms such as the proteinase inhibitor induction (Wildon et al., 1992) and jasmonates signaling pathway (Mousavi et al., 2013). The $\mathrm{AP}$ is a rapid and transient depolarization (a few seconds to $2 \mathrm{~min}$ ) of the plasma membrane with all-or-nothing characteristics, propagating with a tissue-specific rate and without decrement (Zawadzki et al., 1991; Fromm and Spanswick, 1993; Stankovic et al., 1998). The signal propagates preferentially through the phloem, which shares common properties with neurons in animals, namely the existence of membrane continuity by which electrical excitations could be transmitted from one cell to another via plasmodesmata, pores connecting the cytoplasm of one cell to that of its neighbour (Fromm and Lautner, 2007; Van Bel et al., 2014). AP has mainly been studied in the context of rapid motor activity of plants, such as carnivorous or Mimosa pudica plants, in which a propagation rate of the order of $5 \mathrm{~cm} . \mathrm{s}^{-1}$ has been measured (Sibaoka, 1969). APs have also been triggered in plants without rapid motor activity such as Lupinus or willow (Paszewski and Zawadzki, 1976; Fromm and Spanswick, 1993).

The rapid propagation of AP could explain the rapid onset of remote responses such as longitudinal growth inhibition observed in plants after stem bending. As highlighted by recent studies, trees are particularly impacted by mechanical stimulations related to wind (AlonsoSerra et al., 2020). Therefore, the aim of this study is to investigate the electrical signals triggered after a transient bending of poplar stems by electrophysiological measurements.

\section{Results}

To test the effect of stem bending on the production of an electrical signal that propagates, the first challenge was to develop an original device (Fig.1) in which the measuring electrodes were kept immobile during the stem bending. In our case, we attached the stem to two fixed points. This mechanical configuration avoided the possible rotation of 
the cross sections of the stem and thus, the movement of its non-solicited part. This ensured that the electrodes were kept totally immobile when the stem was bent.

A single, transient and rapid bending (2s) of the apical part of poplar stem induced a depolarization wave (Fig. 2A) propagating basipetally up to $20 \mathrm{~cm}$ with a significant decrement. The mean amplitude near the flexion point was around $34 \mathrm{mV}(\mathrm{e} 1)$, and dropped to $24 \mathrm{mV}$ after $5 \mathrm{~cm}(\mathrm{e} 3)$, to reach a mean close to zero at $20 \mathrm{~cm}(\mathrm{e} 6=2.6 \mathrm{mV})$ (Fig. 2B). The passage of the depolarization wave was followed by a slight hyperpolarization of the four measuring electrodes closest to the stimulation. Then, a slow (up to 30 minutes) and oscillation-free return to the initial potential was observed. The half-life time of the depolarization wave also decreased with the position of the electrode; from $44.2 \mathrm{~s}$ for e1 (the closest electrode from the bent zone) to $34.3 \mathrm{~s}$ for e3 and $6.8 \mathrm{~s}$ for e6, the farthest electrode (Table 1A). The average propagation speed of the depolarization wave was evaluated between each electrode (Table 1B). Close to the bent zone, the speed ranged from 12.9 to $19.4 \mathrm{~cm} \cdot \mathrm{s}^{-1}$ between $\mathrm{e} 1$ and e3, while it dropped significantly to a range of 5.8 to $3.3 \mathrm{~cm} . \mathrm{s}^{-1}$ between the farthest electrodes e 3 and e6. Triggering and propagation of the electrical signal in response to stem apical bending was found in $100 \%$ of poplars $(\mathrm{N}=10)$.

A transient and rapid bending of the basal stem segment also generated a depolarization wave (Fig. 2C) propagating acropetally up to $20 \mathrm{~cm}$. The mean amplitude near the bent zone was around $32.4 \mathrm{mV}(\mathrm{e} 1)$, and dropped to $21.2 \mathrm{mV}$ after $5 \mathrm{~cm}$ (e3), to finally reach a mean close to zero $(e 6=3 \mathrm{mV}$ ) after $20 \mathrm{~cm}$ (Fig. 2D). Following the depolarization phase a slight hyperpolarization was observed on the four measuring electrodes closest to the stimulation. Then, a slow and oscillation-free return to the initial potential occurred. The halflife time of the depolarization wave also decreased with the position of the electrode; from 51 $\mathrm{s}$ for e1 to $42.3 \mathrm{~s}$ for e3 and $9.7 \mathrm{~s}$ for e6 (Table 1A). The average propagation speed of the depolarization wave was evaluated between each electrode. Close to the bent zone, the speed ranged from 15.1 to $16.9 \mathrm{~cm} . \mathrm{s}^{-1}$ between e1 and e3, while it dropped significantly to a range of 8.4 to $1.2 \mathrm{~cm} . \mathrm{s}^{-1}$ between the farthest electrodes e3 and e6 (Table 1B). As with the bending of the apical segment, triggering and propagation of the electrical signal in response to stem basal bending was found in $100 \%$ of poplars $(\mathrm{N}=10)$.

In order to compare the nature of the electrical signals propagated following different types of stimulation, we therefore tested the response of poplars in the case of a leaf burn. As shown in Fig. 3, a rapid depolarization was observed for each electrode following a leaf burn; starting with those placed closest to the stimulation site. This depolarization wave propagated 
both acropetally and basipetally in the poplar stem. The return to the initial potential was slow (5 to 45 minutes) and irregular. The amplitude tended to be greater near the stimulation, ranging from 5 to $70 \mathrm{mV}$. The propagation speed was about $0.02 \mathrm{~cm} \cdot \mathrm{s}^{-1}$.

As complementary experiments, we tried to generate an AP by applying cold water to the stem on eight different poplars individuals (Fig. 4). Whereas three plants did not react, a local depolarization (no propagation) was measured on four of them, with a mean amplitude of $21.3 \mathrm{mV} \pm 5.5$. Only one plant showed a clear depolarization event propagating over a distance of at least $1 \mathrm{~cm}$ but less than $3 \mathrm{~cm}$ with a velocity of around $0.5 \mathrm{~cm} . \mathrm{s}^{-1}$ and an amplitude of $30 \mathrm{mV}$.

\section{Discussion}

We studied this signaling following three types of stimulations, each triggering electrical signals with different characteristics. In response to a leaf burn, a depolarization typical of a SW was generated in the poplar trees (Fig. 3). The characteristics of this SW are identical than those described in the literature for herbaceous species: a fast depolarization that tends to decrease with distance followed by a slow and irregular return to the initial potential and a propagation velocity of the order of $0.01 \mathrm{~cm} . \mathrm{s}^{-1}$ (Sambeek and Pickard, 1976; Roblin and Bonnemain, 1985; Julien et al., 1991). On the one hand, the recording of the SW in response to wounding allows validating our experimental setup used for measuring the propagation of electrical signals in poplar. On the other hand, the comparison of the two electrical responses clearly suggests that the one caused by the bending of the stem is not a slow wave.

The shape of the electrical response induced by stem bending, a rapid depolarization followed by a repolarization at the initial potential, shows similarities with AP as described by Pickard, 1973. The maximum amplitude reached near the bent zone was around $34 \mathrm{mV}$; a low value compared to AP measured in various plant species. The position of the six electrodes along the stem allowed following the electrical signal over a distance of $20 \mathrm{~cm}$. These measurements enlightened a significant attenuation of the amplitude and velocity with the increasing distance from the stimulation point (Figs. 2B; 2D and Table 1B). On the contrary, the literature reports that the plant AP propagates at constant rate and without decrement (Sukhov et al., 2018). Although very few studies have focused on studying it over a distance greater than $10 \mathrm{~cm}$, this was observed by Zawadzki et al. (1991) where an AP electrically generated on a stem of Helianthus annuus propagates over at least $15 \mathrm{~cm}$ of stem at constant 
rate and without decrement, later confirmed by Stankovic et al. (1998). This decrement is a first major difference that distinguishes our signal from a classical plant AP.

Despite its action potential-like shape, the electrical response recorded following stem bending does not match with the definition of AP: it differs by the slow decreasing of the amplitude during the propagation of the signal. Morever, it differs from the cold induced putative action potential described in Populus trichocarpa by a speed 30 times higher (Lautner et al., 2005). Furthermore, the amplitude of the AP observed by Lautner et al., (2005) did not seem to show a decrement, although it is not specified if the distance between the two electrodes was higher or less than $10 \mathrm{~cm}$. To take into account this typical characteristic of bending-induced electrical response, we propose to descriptively call this electrical signal as a 'gradual' potential.

We propose two hypotheses to explain the decrement of the 'gradual' potential. The first hypothesis assumes an electrotonic propagation of the 'attenuated' potential. In this case, the decrement can be explained by the poor performance of the excitable and connected cells (especially the phloem) as a propagation medium for an electrical signal. Indeed, the electrical resistance caused by the shrinkage of the membrane at the plasmodesmata, and the capacitance of the non-myelinated membrane (companion cells) cause the dissipation of the electrical signal (Hedrich et al., 2016). The possible re-amplification of the signal along the phloem by voltage-dependent channels would then not be sufficient to compensate for this dissipation. Indeed, no equivalent to Ranvier's nodes has been identified in plants to date. The transmission of the excited state to neighboring cells would tend to decrease, which could account for the drop in propagation speed. The second hypothesis suggests that the 'gradual' potential observed following a transient bending of the stem could result from the opening of mechanosensitive channels following the passage of a hydraulic pressure wave in the vascular tissues, itself induced by the bending (Lopez et al., 2014, Louf et al., 2017). This hydraulic pulse is itself attenuated over the distance because of lateral leaks and the mechanical flexibility of the pipes, which absorb some of the initial energy.

\section{Conclusion}

Transient bending of poplar stems generates a rapid depolarization wave that to propagates rapidly up to $20 \mathrm{~cm}$ from the stimulation zone with decrement. The characteristics of this depolarization wave do not fit with the definitions neither of a slow wave nor of the well-known action potential. Also, we propose to call this signal 'gradual' potential. Its 
propagation mechanism remains unknown. That is why current research is now focusing on the hypothesis of hydro-electric coupling.

\section{Materials and methods}

\section{Plant material and culture conditions}

Young poplars (Populus tremula $\times$ alba, clone INRA 717-1B4) were obtained by in vitro micropropagation (Leple et al., 1992). Once they reached a height of about $4 \mathrm{~cm}$, they were gradually acclimatized on a hydroponic solution (Martin et al., 2009) through decreasing relative humidity. Trees were then placed in a growth chamber $(16 \mathrm{~h} / 8 \mathrm{~h}$ light/dark cycle at 40 $\mu \mathrm{mol} . \mathrm{m}^{-2} \cdot \mathrm{s}^{-1}$ and $22{ }^{\circ} \mathrm{C} / 18{ }^{\circ} \mathrm{C}$ with air relative humidity of $60 \%$ ). Four months after micropropagation, the poplars were used for experiments: at this stage, stems were about 77.8 $\mathrm{cm}( \pm 1.5 \mathrm{SE})$ tall with an average diameter of $5.8 \mathrm{~mm}( \pm 0.3 \mathrm{SE})$.

Prior to electrophysiology experiments plants were moved into a Faraday cage in ambient laboratory $\left(16 \mathrm{~h} / 8 \mathrm{~h}\right.$ light/dark cycle at $20 \mu \mathrm{mol} . \mathrm{m}^{-2} \cdot \mathrm{s}^{-1}$ and $\left.22{ }^{\circ} \mathrm{C} / 20{ }^{\circ} \mathrm{C}\right)$. Plants were set vertically and fixed in two points of the stem with clamping rings (Fig. 1). Foam was rolled around each part of the stem before tightening the clamping rings to avoid stem wounds and to allow possible stem diameter variations. The root system was plunged in a $20 \mathrm{~L}$ vat filled with hydroponic solution.

\section{Bending treatments}

The leaves of the bent segment were removed with a razor blade to avoid uncontrolled mechanical stimuli. The speed and the magnitude of the bending stimulation were controlled by a motorized arm (hybrid stepping motors 17PM-H311-P1, Minebea.Co) that pushed the stem against a plastic template; which had a constant radius of curvature. The speed of the motor was fixed in order to manage a flexion time of $2 \mathrm{~s}$ (round trip) using interface software MegunoLink. The strain magnitude on the stem periphery was controlled by the radius of curvature of the plastic template. This method allowed applying the same strain level along 12 $\mathrm{cm}$ of the bent segment. The setup was adjusted in order to apply a maximal peripheral longitudinal strain of the bark of around 2\% (Moulia et al., 2015). This value is high enough to generate significant thigmomorphogenetic responses (Niez et al., 2019).

Two types of bending treatments were applied. For transient apical bending, the template was placed $35 \mathrm{~cm}$ below the apex (Fig. 1A). For transient basal bending, the template was placed $25 \mathrm{~cm}$ above the roots (Fig. 1B). 


\section{Burning treatment}

The burn was carried out at a leaflet along the midrib with a match. The flame was held $1 \mathrm{~cm}$ below the leaflet for 4 to 6 seconds.

\section{Cold treatment}

The cold treatment was applied by placing a drop of cold water $\left(5^{\circ} \mathrm{C}\right)$ with a pipet tip near the upper clamping ring.

\section{Monitoring of extracellular electrical signals}

In order to minimize artefactual interferences, one single poplar was placed in a Faraday cage. All electronic materials were located outside the cage. Six measuring electrodes (tinned copper wire (359-835), $0.25 \mathrm{~mm}$ diameter, RS Components) were inserted into the stem, passing through all the tissue to the pith, and measured electrical potential simultaneously near the bending area and up to $20 \mathrm{~cm}$ from it. After the installation was completed, the plant was left undisturbed for stabilization during 24 to 48 hours.

The reference electrode (RC3 model, World Precision Instruments) was made of an $\mathrm{Ag} / \mathrm{AgCl}$ wire immersed in the nutrient solution of the plants. The electrical potential recorded is the difference between a measuring electrode and the reference electrode with respect to ground. The first measuring electrode e1 was inserted $2 \mathrm{~cm}$ below (apical bending) or above (basal bending) the stem-to-template contact (Fig. 1). The respective distances of each electrode from e1 were $2 \mathrm{~cm}(\mathrm{e} 2), 5 \mathrm{~cm}(\mathrm{e} 3), 10 \mathrm{~cm}(\mathrm{e} 4), 15 \mathrm{~cm}(\mathrm{e} 5)$, and $20 \mathrm{~cm}(\mathrm{e} 6)$. The six measuring electrodes and the reference electrode were connected to a cDAQ-9171 (National Instrument) electronic card. The electronic card was used as an impedance amplifier (10 G $\Omega$ ) and A/D converter. DAQExpress 1.0.1 software (National Instrument) monitored the potential difference with a sampling rate of $200 \mathrm{~Hz}$. The graphs and analyzes were built using MatLab® software.

The analysis of the recordings provided several parameters of the signal. The amplitude was defined as the maximum difference value compared to the baseline before bending. The half-life time of the signal was defined as the duration at half amplitude (Fig. 2A). The average propagation speed of the signal was calculated between each electrode as the ratio of the distance between two consecutive electrodes to the delay between the detection of a change in potential difference.

\section{Statistical analysis}


All measured and computed data were statistically analysed using R software. Kruskal and Wallis's tests and Dunn's tests were performed to compare results in terms of amplitude, duration and speed of the signal $(\mathrm{p}<0.05)$.

\section{Acknowledgments}

The authors thank Brigitte Girard, Romain Souchal, Stephane Ploquin, Amélie Coston and

Juliette Tinturier for their technical support. And thank Rémi Cadet, Jean-Marie Frachisse, Yoël Forterre and Bertrand Coste for the fruitful discussions.

\section{Tables}

Table 1. Evolution of the half-life time (A) and the mean of the propagation speed (B) of a depolarization wave induced by an apical or basal bending of the stem.

270 A

\begin{tabular}{|c|c|c|}
\hline \multirow{2}{*}{$\begin{array}{c}\text { Electrode } \\
\text { number }\end{array}$} & \multicolumn{2}{|c|}{ Half-life time (s) } \\
\cline { 2 - 3 } & Apical bending & Basal bending \\
\hline e1 & $44.2 \pm 6.7$ & $51 \pm 8.3$ \\
\hline e2 & $32.9 \pm 4.5$ & $43.3 \pm 7.1$ \\
\hline e3 & $34.3 \pm 3.5$ & $42.3 \pm 4.4$ \\
\hline e4 & $21.6 \pm 5$ & $35 \pm 3.6$ \\
\hline e5 & $15.1 \pm 4.9$ & $32.3 \pm 3.9$ \\
\hline e6 & $6.8 \pm 4.4$ & $9.7 \pm 9.7$ \\
\hline
\end{tabular}

\begin{tabular}{|c|c|c|}
\hline \multirow{2}{*}{$\begin{array}{c}\text { Interval from } \\
\text { the bent-zone }\end{array}$} & \multicolumn{2}{|c|}{ Average speed $\left(\mathrm{cm}^{\mathbf{1}}{ }^{-\mathbf{1}}\right)$} \\
\cline { 2 - 3 }$(\mathbf{c m})$ & Apical bending & Basal bending \\
\hline$[0 ; 2]$ & $12.98 \pm 2.4$ & $15.12 \pm 5.4$ \\
\hline$[2 ; 5]$ & $19.41 \pm 3.8$ & $16.87 \pm 2.7$ \\
\hline$[5 ; 10]$ & $5.85 \pm 1.7$ & $12.27 \pm 2.7$ \\
\hline$[10 ; 15]$ & $3.31 \pm 1.7$ & $8.43 \pm 1.1$ \\
\hline$[15 ; 20]$ & $3.36 \pm 2.7$ & $1.19 \pm 1.2$ \\
\hline
\end{tabular}




\section{$274 \quad$ Figure legends}

275 Figure 1: Experimental designs for measuring electrical signals in stem after an apical (A) or a basal (B) transient bending. The poplar tree is placed in a Faraday cage; fxed in two points of the stem with clamping rings (r). The roots incubate in a nutrient solution. The stem is bent at $2.5 \mathrm{~cm}$.s-1 with a motorized arm $(\mathrm{m})$ that pushes the stem along a plastic constantcurvature template (t) . The electrodes are placed in the immobile portion of the stem. Electrode e1 is inserted $2 \mathrm{~cm}$ below the stem-template contact. Then the distances are: e1-e2 = $2 \mathrm{~cm}$, e2$=3 \mathrm{~cm}, \mathrm{e} 3-\mathrm{e} 4=5 \mathrm{~cm}, \mathrm{e} 4-\mathrm{e} 5=5 \mathrm{~cm}$ and $\mathrm{e} 5-\mathrm{e} 6=5 \mathrm{~cm}$. The potential difference is monitored along $20 \mathrm{~cm}$ of straight stem, below (A) or above (B) the bent region.

Figure 2: Monitoring of the electrical signal generated after a transient stem bending and recorded at different positions in the stem in Poplar tremula $x$ alba. Recording of the electrical signals measured by the six electrodes after a transient apical (A) or basal (C) stem bending applied on the stem (arrow). The half-life time of the signal was defned as the time during which the signal is higher than half the maximal amplitude. Evolution of the amplitude of depolarization wave after apical (B) or basale (D) stem bending depending on the distance from the bent-zone. Values represent the mean $( \pm \mathrm{SE}),(\mathrm{n}=10)$. Letters indicate the values that are statistically different (Kruskal and Wallis's tests and Dunn's tests $\mathrm{p}<0.05$ ).

Figure 3 : Monitoring of the electrical signal generated after a burnt leaf (bl) in Poplar slow and irregular return to the initial potential. Here the amplitude ranges between 20 to $70 \mathrm{mV}$ and the velocity is around $0.02 \mathrm{~cm} . \mathrm{s}-1$ (A). The time of the stimulation is indicated by the black arrow. The poplar tree is placed in a Faraday cage; fxed in two points of the stem with clamping rings (r). Stimulation consists of burning the leaf with a match for about $4 \mathrm{~s}$ (B). The electrodes are placed along the stem as follows: e1-e $2=2 \mathrm{~cm}, \mathrm{e} 2-\mathrm{e} 3=3 \mathrm{~cm}$, e $3-\mathrm{e} 4=5 \mathrm{~cm}$, e4-e $5=5 \mathrm{~cm}$ and $\mathrm{e} 5-\mathrm{e} 6=5 \mathrm{~cm}$.

Figure 4 : Monitoring of the electrical signal generated after the application of droplet of water at $5^{\circ} \mathbf{C}$ to the stem (w) in Poplar tremula $\boldsymbol{x}$ alba. The time of the stimulation is indicated by the black arrow (A). The poplar tree is placed in a Faraday cage; fxed in two points of the stem with clamping rings (r). The electrodes are placed along the stem as follows: e1-e $2=2 \mathrm{~cm}$, $\mathrm{e} 2-\mathrm{e} 3=3 \mathrm{~cm}$ and $\mathrm{e} 3-\mathrm{e} 4=5 \mathrm{~cm}(\mathrm{~B})$.

\section{References}

Alonso-Serra J, Shi X, Peaucelle A, Rastas P, Bourdon M, Immanen J, Takahashi J, Koivula H, Eswaran G, Muranen S, et al (2020) ELIMÄKI Locus Is Required for Vertical Proprioceptive Response in Birch Trees. Curr Biol 30: 589-599.e5

Van Bel AJE, Ehlers K (2018) Electrical Signalling via Plasmodesmata. Annu. Plant Rev. 
online. John Wiley \& Sons, Ltd, Chichester, UK, pp 263-278

Van Bel AJE, Furch ACU, Will T, Buxa S V., Musetti R, Hafke JB (2014) Spread the news: Systemic dissemination and local impact of $\mathrm{Ca} 2+$ signals along the phloem pathway. J Exp Bot 65: 1761-1787

Choi W-G, Hilleary R, Swanson SJ, Kim S-H, Gilroy S (2016) Rapid, Long-Distance Electrical and Calcium Signaling in Plants. Annu Rev Plant Biol 67: 287-307

Coutand C, Julien JL, Moulia B, Mauget JC, Guitard D (2000) Biomechanical study of the effect of a controlled bending on tomato stem elongation: global mechanical analysis. J Exp Bot 51: 1813-1824

Coutand C, Martin L, Leblanc-Fournier N, Decourteix M, Julien JL, Moulia B (2009) Strain Mechanosensing Quantitatively Controls Diameter Growth and PtaZFP2 Gene Expression in Poplar. Plant Physiol 151: 223-232

Coutand C, Moulia B (2000) Biomechanical study of the effect of a controlled bending on tomato stem elongation: local strain sensing and spatial integration of the signal. J Exp Bot 51: 1825-1842

Farmer EE, Gasperini D, Acosta IF (2014) The squeeze cell hypothesis for the activation of jasmonate synthesis in response to wounding. New Phytol 204: 282-288

Fromm J, Lautner S (2007) Electrical signals and their physiological significance in plants. Plant Cell Environ 30: 249-257

Fromm J, Spanswick R (1993) Characteristics of Action Potentials in Willow ( Salix viminalis L.). J Exp Bot 44: 1119-1125

Hedrich R, Salvador-Recatalà V, Dreyer I (2016) Electrical Wiring and Long-Distance Plant Communication. Trends Plant Sci 21: 376-387

Jaffe MJ (1973) Thigmomorphogenesis: The response of plant growth and development to mechanical stimulation. Planta 114: 143-157

Julien J-L (1993) Caracterisation electrophysiologique de l'onde de depolarisation declenchee par un traumatisme chez bidens pilosa l. http://www.theses.fr

Julien JL, Desbiez MO, De Jaegher G, Frachisse JM (1991) Characteristics of the Wave of Depolarization Induced by Wounding in Bidens pilosa L. J Exp Bot 42: 131-137

Kern KA, Ewers FW, Telewski FW, Koehler L (2005) Mechanical perturbation affects conductivity, mechanical properties and aboveground biomass of hybrid poplars. Tree Physiol 25: 1243-1251

Lautner S, Grams TEE, Matyssek R, Fromm J (2005) Characteristics of electrical signals in poplar and responses in photosynthesis. Plant Physiol 138: 2200-2209

Leple JC, Brasileiro ACM, Michel MF, Delmotte F, Jouanin L (1992) Transgenic poplars: expression of chimeric genes using four different constructs. Plant Cell Rep 11: 137-141

Lopez R, Badel E, Peraudeau S, Leblanc-Fournier N, Beaujard F, Julien JL, Cochard H, Moulia B (2014) Tree shoot bending generates hydraulic pressure pulses: A new long-distance signal? J Exp Bot 65: 1997-2008

Louf J-F, Guéna G, Badel E, Forterre Y (2017) Universal poroelastic mechanism for 
hydraulic signals in biomimetic and natural branches. Proc Natl Acad Sci U S A 114: 11034-11039

Malone M (1993) Hydraulic Signals. Philos Trans R Soc London Ser B-Biological Sci 341: 33-39

Morizet J, Mingeau M (1976) Effect of environment on water-uptake, as studied on beheaded exudating tomato. 1. Role of nutrients. Ann Agron 27: 183-205

Moulia B, Coutand C, Julien JL (2015) Mechanosensitive control of plant growth: Bearing the load, sensing, transducing, and responding. Front Plant Sci 6: 52

Mousavi SAR, Chauvin A, Pascaud F, Kellenberger S, Farmer EE (2013) GLUTAMATE RECEPTOR-LIKE genes mediate leaf-to-leaf wound signalling. Nature 500: 422-426

Niez B, Dlouha J, Bruno Moulia •, Badel E (2019) Water-stressed or not, the mechanical acclimation is a priority requirement for trees. 33: 279-291

Paszewski A, Zawadzki T (1976) Action Potentials in Lupinus angustifolius L. Shoots. J Exp Bot 27: 369-374

Pickard BG (1973) Action potentials in higher plants. Bot Rev 39: 172-201

Roblin G, Bonnemain J-L (1985) Propagation in <italic $>$ Vicia faba</italic> Stem of a Potential Variation Induced by Wounding. Plant Cell Physiol 26: 1273-1283

Roignant J, Badel É, Leblanc-Fournier N, Brunel-Michac N, Ruelle J, Moulia B, Decourteix M (2018) Feeling stretched or compressed? the multiple mechanosensitive responses of wood formation to bending. Ann Bot 121: 1151-1161

Sambeek JW Van, Pickard BG (1976a) Mediation of rapid electrical, metabolic, transpirational, and photosynthetic changes by factors released from wounds. I. Variation potentials and putative action potentials in intact plants. Can J Bot 54: 2642-2650

Sambeek JW Van, Pickard BG (1976b) Mediation of rapid electrical, metabolic, transpirational, and photosynthetic changes by factors released from wounds. III. Measurements of CO 2 and H 2 O flux. Can J Bot 54: 2662-2671

Sambeek JW Van, Pickard BG, Ulbright CE (1976) Mediation of rapid electrical, metabolic, transpirational, and photosynthetic changes by factors released from wounds. II. Mediation of the variation potential by Ricca's factor. Can J Bot 54: 2651-2661

Stankovic B, Witters DL, Zawadzki T, Davies E (1998) Action potentials and variation potentials in sunflower: An analysis of their relationships and distinguishing characteristics. Physiol Plant 103: 51-58

Sukhov V, Sukhova E, Vodeneev V (2019) Long-distance electrical signals as a link between the local action of stressors and the systemic physiological responses in higher plants. Prog Biophys Mol Biol 146: 63-84

Telewski FW (2006) A unified hypothesis of mechanoperception in plants. Am J Bot 93: 1466-1476

Telewski, W. F (1995) Wind-induced physiological and deveop-mental responses in trees. Wind Tree 237-263

Trebacz K, Dziubinska H, Krol E (2006) Electrical signals in long-distance communication 
in plants. Commun. Plants Neuronal Asp. Plant Life. Springer Berlin Heidelberg, Berlin, Heidelberg, pp 277-290

Wacke M, Thiel G (2001) Electrically triggered all-or-none Ca2+-liberation during action potential in the giant alga Chara. J Gen Physiol 118: 11-21

Zawadzki T, Davies E, Dziubinska H, Trebacz K (1991) Characteristics of action 
A

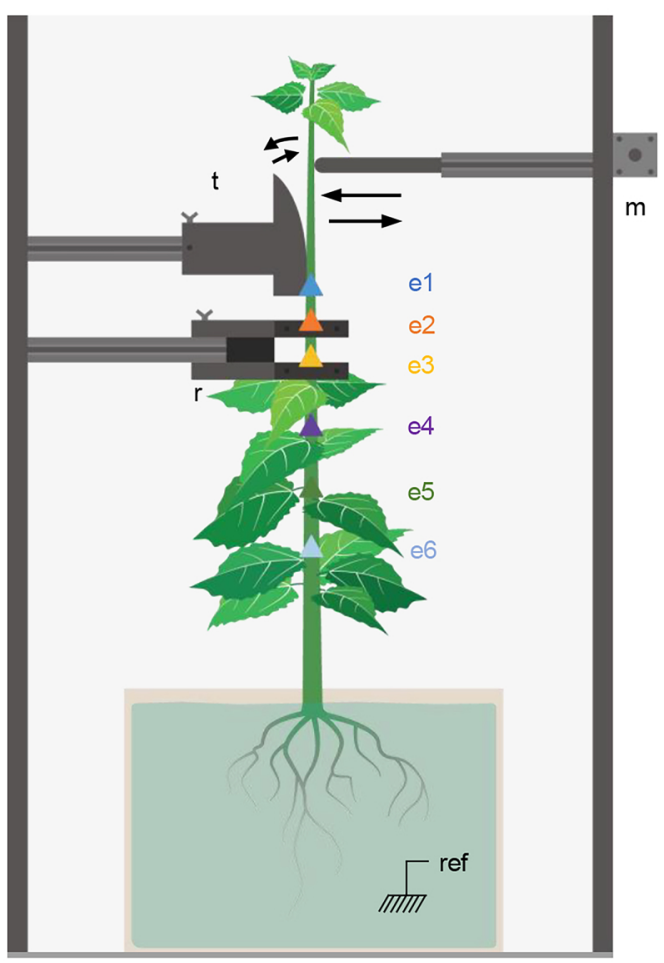

B

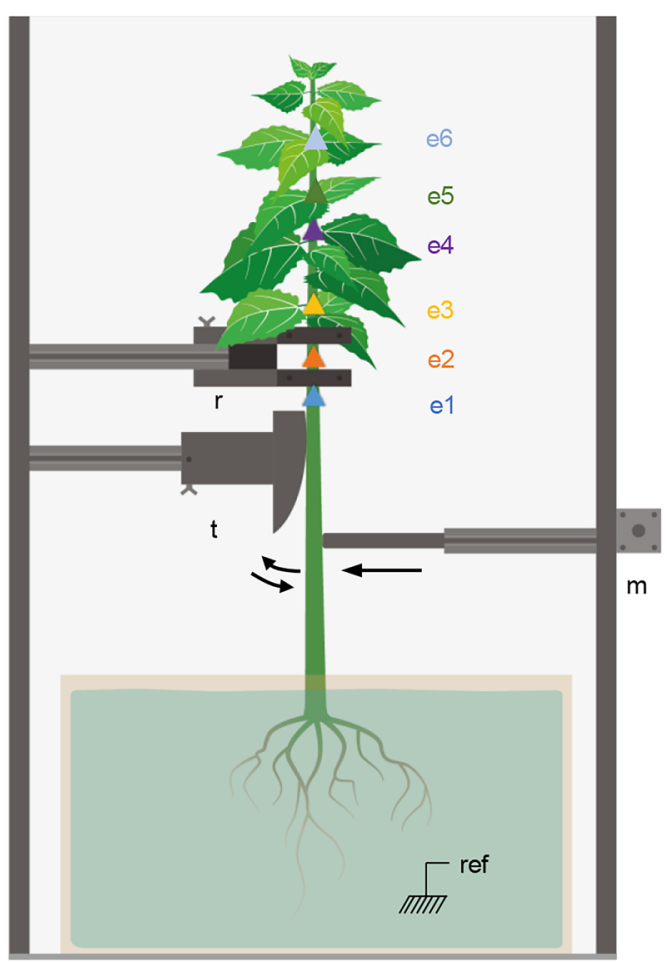

Figure 1: Experimental designs for measuring electrical signals in stem after an apical (a and b) or a basal (c) transient bending. The poplar tree is placed in a Faraday cage; fixed in two points of the stem with clamping rings ( $r$ ). The roots incubate in a nutrient solution. The stem is bent at $2,5 \mathrm{~cm} \cdot \mathrm{s}^{-1}$ with a motorized arm $(\mathrm{m})$ that pushes the stem along a plastic constant-curvature template $(\mathrm{t})$. The electrodes are placed in the immobile portion of the stem. Electrode e1 is inserted $2 \mathrm{~cm}$ below the stem-template contact. Then the distances are : e 1-e $2=2 \mathrm{~cm}, \mathrm{e} 2-\mathrm{e} 3=3 \mathrm{~cm}, \mathrm{e} 3-\mathrm{e} 4=5 \mathrm{~cm}$, e4-e5 $=5 \mathrm{~cm}$ and e $5-\mathrm{e} 6=5 \mathrm{~cm}$. The potential difference is monitored along $20 \mathrm{~cm}$ of straight stem, below (b) or above (c) the bent region. 


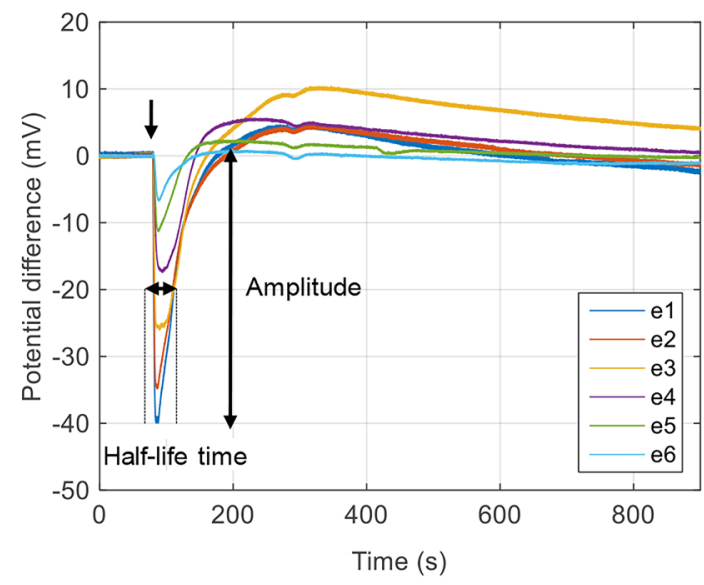

C

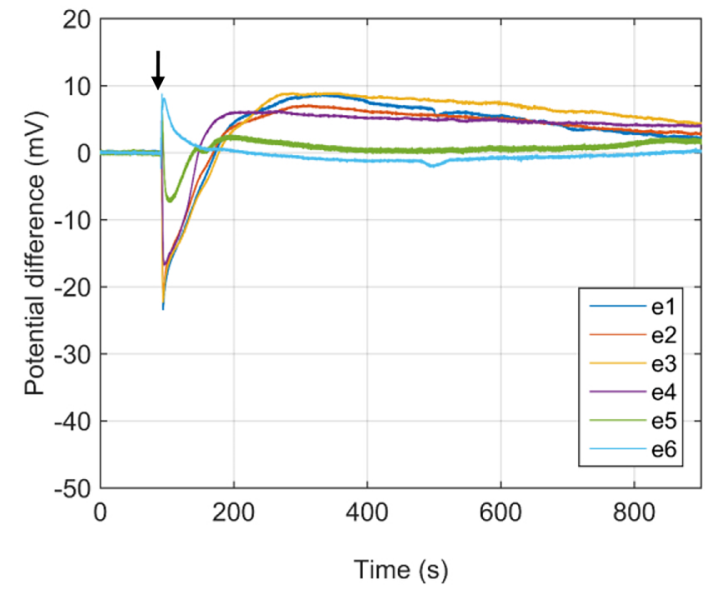

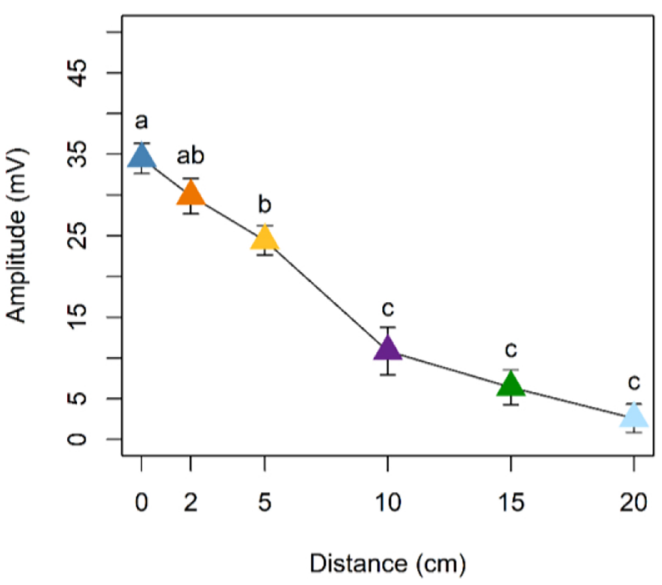

D

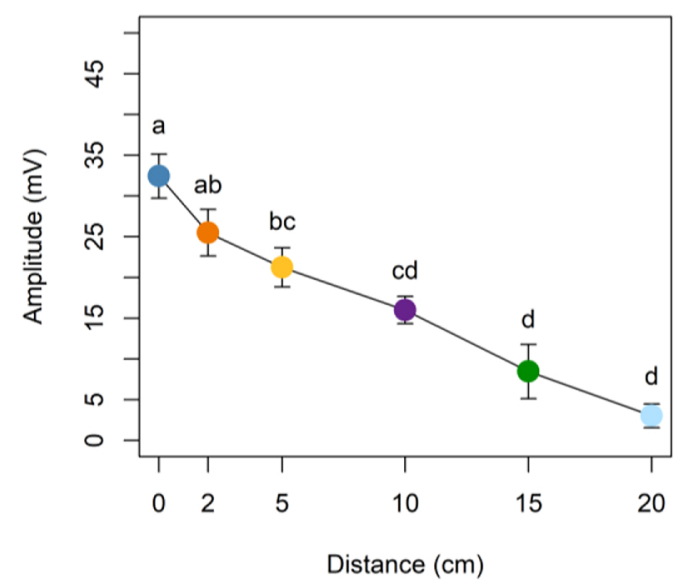

Figure 2: Monitoring of the electrical signal generated after a transient stem bending and recorded at different positions in the stem in Poplar tremula $x$ alba. Recording of the electrical signals measured by the 6 electrodes after a transient apical (A) or basal (C) stem bending applied on the stem (arrow). The half-life time of the signal was defined as the time during which the signal is higher than half the maximal amplitude. Evolution of the amplitude of depolarization wave after apical (B) or basale (D) stem bending depending on the distance from the bent-zone. Values represent the mean $( \pm S E),(n=10)$. Letters indicate the values that are statistically different (Kruskal and Wallis's tests and Dunn's tests $p<$ 0.05). 
Table 1: Evolution of the half-life time (A) and the mean of the propagation speed (B) of a depolarization wave induced by an apical or basal bending of the stem.

A

\begin{tabular}{|c|r|r|}
\hline \multirow{2}{*}{$\begin{array}{c}\text { Electrode } \\
\text { number }\end{array}$} & \multicolumn{2}{|c|}{ Half-life time (s) } \\
\cline { 2 - 3 } & Apical bending & Basal bending \\
\hline e1 & $44,2 \pm 6,7$ & $51 \pm 8,3$ \\
\hline e2 & $32,9 \pm 4,5$ & $43,3 \pm 7,1$ \\
\hline e3 & $34,3 \pm 3,5$ & $42,3 \pm 4,4$ \\
\hline e4 & $21,6 \pm 5$ & $35 \pm 3,6$ \\
\hline e5 & $15,1 \pm 4,9$ & $32,3 \pm 3,9$ \\
\hline e6 & $6,8 \pm 4,4$ & $9,7 \pm 9,7$ \\
\hline
\end{tabular}

B

\begin{tabular}{|c|r|r|}
\hline \multirow{2}{*}{$\begin{array}{c}\text { Interval } \\
\text { from the } \\
\text { bent-zone } \\
\text { (cm) }\end{array}$} & \multicolumn{2}{|c|}{ Average speed (cm.s ${ }^{-1}$ ) } \\
\cline { 2 - 3 } & Apical bending & Basal bending \\
\hline$[0 ; 2]$ & $12,98 \pm 2,4$ & $15,12 \pm 5,4$ \\
\hline$[2 ; 5]$ & $19,41 \pm 3,8$ & $16,87 \pm 2,7$ \\
\hline$[5 ; 10]$ & $5,85 \pm 1,7$ & $12,27 \pm 2,7$ \\
\hline$[10 ; 15]$ & $3,31 \pm 1,7$ & $8,43 \pm 1,1$ \\
\hline$[15 ; 20]$ & $3,36 \pm 2,7$ & $1,19 \pm 1,2$ \\
\hline
\end{tabular}



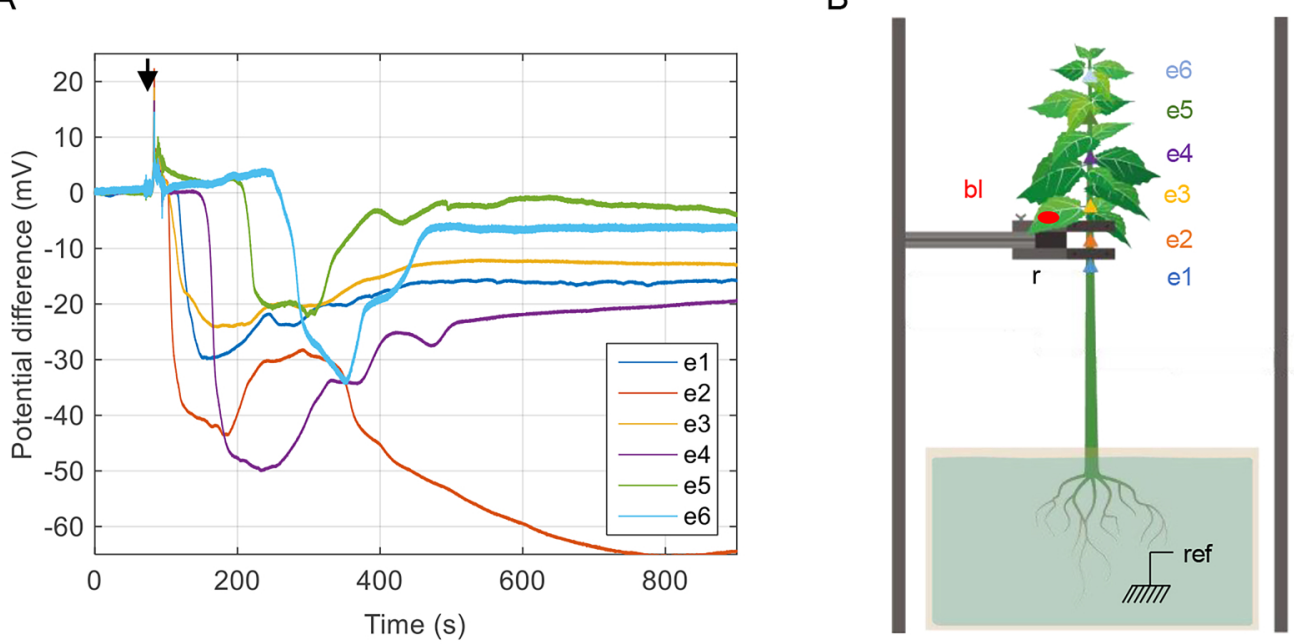

Figure 3 : Recording of a slow wave propagating from a burnt leaf (bl). The poplar tree is placed in a Faraday cage; fixed in two points of the stem with clamping rings ( $r$ ). Stimulation consists of burning the leaf with a match for about $4 \mathrm{~s}$. The time of the stimulation is indicated by the black arrow. The electrodes are placed along the stem as follow : e1-e2 $=2 \mathrm{~cm}$, e2-e3 $=3 \mathrm{~cm}$, e3-e4 $=5 \mathrm{~cm}$, e4-e5 $=5 \mathrm{~cm}$ and e5-e $6=5 \mathrm{~cm}$. For each electrode, slow wave consists in a fast depolarization followed by a slow and irregular return to the initial potential. Here the amplitude ranges between 20 to $70 \mathrm{mV}$ and the velocity is around $0.02 \mathrm{~cm} . \mathrm{s}^{-1}$. 
A

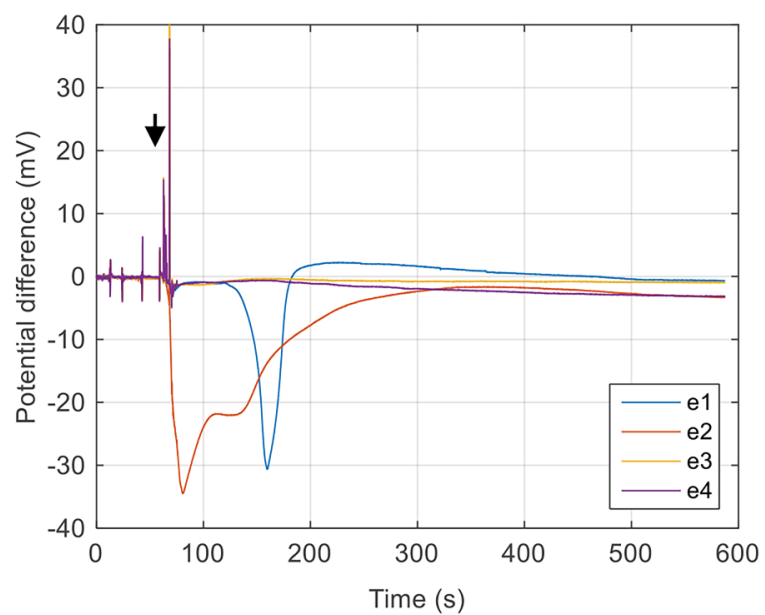

B

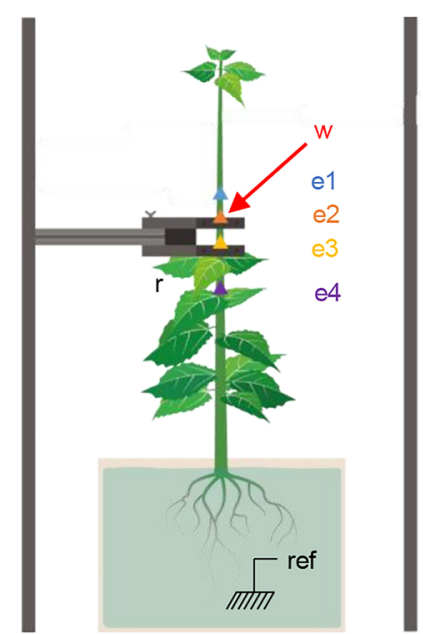

Figure 4 : Recording of an action potential in response to the application of droplet of water at $5^{\circ} \mathrm{C}$ to the stem (w). The poplar tree is placed in a Faraday cage; fixed in two points of the stem with clamping rings $(r)$. The time of the stimulation is indicated by the black arrow. The electrodes are placed along the stem as follow : e1-e2 $=2 \mathrm{~cm}, \mathrm{e} 2-\mathrm{e} 3=3$ $\mathrm{cm}, \mathrm{e} 3-\mathrm{e} 4=5 \mathrm{~cm}, \mathrm{e} 4-\mathrm{e} 5=5 \mathrm{~cm}$ and $\mathrm{e} 5-\mathrm{e} 6=5 \mathrm{~cm}$. 


\section{Parsed Citations}

Alonso-Serra J, Shi X, Peaucelle A, Rastas P, Bourdon M, Immanen J, Takahashi J, Koivula H, Eswaran G, Muranen S, et al (2020) ELIMÄKI Locus Is Required for Vertical Proprioceptive Response in Birch Trees. Curr Biol 30: 589-599.e5

Google Scholar: Author Only Title Only Author and Title

Van Bel AJE, Ehlers K (2018) Electrical Signalling via Plasmodesmata. Annu. Plant Rev. online. John Wiley \& Sons, Ltd, Chichester, UK, pp 263-278

Google Scholar: Author Only Title Only Author and Title

Van Bel AJE, Furch ACU, Will T, Buxa S V., Musetti R, Hafke JB (2014) Spread the news: Systemic dissemination and local impact of $\mathrm{Ca2+}$ signals along the phloem pathway. J Exp Bot 65: 1761-1787

Google Scholar: Author Only Title Only Author and Title

Choi W-G, Hilleary R, Swanson SJ, Kim S-H, Gilroy S (2016) Rapid, Long-Distance Electrical and Calcium Signaling in Plants. Annu Rev Plant Biol 67: 287-307

Google Scholar: Author Only Title Only Author and Title

Coutand C, Julien JL, Moulia B, Mauget JC, Guitard D (2000) Biomechanical study of the effect of a controlled bending on tomato stem elongation: global mechanical analysis. J Exp Bot 51: 1813-1824

Google Scholar: Author Only Title Only Author and Title

Coutand C, Martin L, Leblanc-Fournier N, Decourteix M, Julien JL, Moulia B (2009) Strain Mechanosensing Quantitatively Controls Diameter Growth and PtaZFP2 Gene Expression in Poplar. Plant Physiol 151: 223-232

Google Scholar: Author Only Title Only Author and Title

Coutand C, Moulia B (2000) Biomechanical study of the effect of a controlled bending on tomato stem elongation: local strain sensing and spatial integration of the signal. J Exp Bot 51: 1825-1842

Google Scholar: Author Only Title Only Author and Title

Farmer EE, Gasperini D, Acosta IF (2014) The squeeze cell hypothesis for the activation of jasmonate synthesis in response to wounding. New Phytol 204: 282-288

Google Scholar: Author Only Title Only Author and Title

Fromm J, Lautner S (2007) Electrical signals and their physiological significance in plants. Plant Cell Environ 30: 249-257

Google Scholar: Author Only Title Only Author and Title

Fromm J, Spanswick R (1993) Characteristics of Action Potentials in Willow ( Salix viminalis L.). J Exp Bot 44: 1119-1125

Google Scholar: Author Only Title Only Author and Title

Hedrich R, Salvador-Recatalà V, Dreyer I (2016) Electrical Wiring and Long-Distance Plant Communication. Trends Plant Sci 21: 376 387

Google Scholar: Author Only Title Only Author and Title

Jaffe MJ (1973) Thigmomorphogenesis: The response of plant growth and development to mechanical stimulation. Planta 114: 143-157 Google Scholar: Author Only Title Only Author and Title

Julien J-L (1993) Caracterisation electrophysiologique de l'onde de depolarisation declenchee par un traumatisme chez bidens pilosa I. http://www.theses.fr

Google Scholar: Author Only Title Only Author and Title

Julien JL, Desbiez MO, De Jaegher G, Frachisse JM (1991) Characteristics of the Wave of Depolarization Induced by Wounding in Bidens pilosa L. J Exp Bot 42: 131-137

Google Scholar: Author Only Title Only Author and Title

Kern KA, Ewers FW, Telewski FW, Koehler L (2005) Mechanical perturbation affects conductivity, mechanical properties and aboveground biomass of hybrid poplars. Tree Physiol 25: 1243-1251

Google Scholar: Author Only Title Only Author and Title

Lautner S, Grams TEE, Matyssek R, Fromm J (2005) Characteristics of electrical signals in poplar and responses in photosynthesis.

Plant Physiol 138: 2200-2209

Google Scholar: Author Only Title Only Author and Title

Leple JC, Brasileiro ACM, Michel MF, Delmotte F, Jouanin L (1992) Transgenic poplars: expression of chimeric genes using four different constructs. Plant Cell Rep 11: 137-141

Google Scholar: Author Only Title Only Author and Title

Lopez R, Badel E, Peraudeau S, Leblanc-Fournier N, Beaujard F, Julien JL, Cochard H, Moulia B (2014) Tree shoot bending generates hydraulic pressure pulses: A new long-distance signal? J Exp Bot 65: 1997-2008

Louf J-F, Guéna G, Badel E, Forterre Y (2017) Universal poroelastic mechanism for hydraulic signals in biomimetic and natural branches. Proc Natl Acad Sci U S A 114: 11034-11039

Google Scholar: Author Only Title Only Author and Title 
Malone M (1993) Hydraulic Signals. Philos Trans R Soc London Ser B-Biological Sci 341: 33-39

Google Scholar: Author Only Title Only Author and Title

Morizet J, Mingeau M (1976) Effect of environment on water-uptake, as studied on beheaded exudating tomato. 1. Role of nutrients. Ann Agron 27: 183-205

Google Scholar: Author Only Title Only Author and Title

Moulia B, Coutand C, Julien JL (2015) Mechanosensitive control of plant growth: Bearing the load, sensing, transducing, and responding. Front Plant Sci 6: 52

Google Scholar: Author Only Title Only Author and Title

Mousavi SAR, Chauvin A, Pascaud F, Kellenberger S, Farmer EE (2013) GLUTAMATE RECEPTOR-LIKE genes mediate leaf-to-leaf wound signalling. Nature 500: 422-426

Google Scholar: Author Only Title Only Author and Title

Niez B, Dlouha J, Bruno Moulia ·, Badel E (2019) Water-stressed or not, the mechanical acclimation is a priority requirement for trees. 33: 279-291

Google Scholar: Author Only Title Only Author and Title

Paszewski A Zawadzki T (1976) Action Potentials in Lupinus angustifolius L. Shoots. J Exp Bot 27: 369-374

Google Scholar: Author Only Title Only Author and Title

Pickard BG (1973) Action potentials in higher plants. Bot Rev 39: 172-201

Google Scholar: Author Only Title Only Author and Title

Roblin G, Bonnemain J-L (1985) Propagation in Vicia faba Stem of a Potential Variation Induced by Wounding. Plant Cell Physiol 26: 1273-1283

Google Scholar: Author Only Title Only Author and Title

Roignant J, Badel É, Leblanc-Fournier N, Brunel-Michac N, Ruelle J, Moulia B, Decourteix M (2018) Feeling stretched or compressed? the multiple mechanosensitive responses of wood formation to bending. Ann Bot 121: 1151-1161

Google Scholar: Author Only Title Only Author and Title

Sambeek JW Van, Pickard BG (1976a) Mediation of rapid electrical, metabolic, transpirational, and photosynthetic changes by factors released from wounds. I. Variation potentials and putative action potentials in intact plants. Can J Bot 54: 2642-2650

Google Scholar: Author Only Title Only Author and Title

Sambeek JW Van, Pickard BG (1976b) Mediation of rapid electrical, metabolic, transpirational, and photosynthetic changes by factors released from wounds. III. Measurements of CO 2 and H 2 O flux. Can J Bot 54: 2662-2671

Google Scholar: Author Only Title Only Author and Title

Sambeek JW Van, Pickard BG, Ulbright CE (1976) Mediation of rapid electrical, metabolic, transpirational, and photosynthetic changes by factors released from wounds. II. Mediation of the variation potential by Ricca's factor. Can J Bot 54: 2651-2661

Google Scholar: Author Only Title Only Author and Title

Stankovic B, Witters DL, Zawadzki T, Davies E (1998) Action potentials and variation potentials in sunflower: An analysis of their relationships and distinguishing characteristics. Physiol Plant 103: 51-58

Google Scholar: Author Only Title Only Author and Title

Sukhov V, Sukhova E, Vodeneev V (2019) Long-distance electrical signals as a link between the local action of stressors and the systemic physiological responses in higher plants. Prog Biophys Mol Biol 146: 63-84

Google Scholar: Author Only Title Only Author and Title

Telewski FW (2006) Aunified hypothesis of mechanoperception in plants. Am J Bot 93: 1466-1476

Google Scholar: Author Only Title Only Author and Title

Telewski, W. F (1995) Wind-induced physiological and deveop-mental responses in trees. Wind Tree 237-263

Google Scholar: Author Only Title Only Author and Title

Trebacz K, Dziubinska H, Krol E (2006) Electrical signals in long-distance communication in plants. Commun. Plants Neuronal Asp.

Plant Life. Springer Berlin Heidelberg, Berlin, Heidelberg, pp 277-290

Google Scholar: Author Only Title Only Author and Title

Wacke M, Thiel G (2001) Electrically triggered all-or-none Ca2+-liberation during action potential in the giant alga Chara. J Gen Physiol 118: 11-21

Google Scholar: Author Only Title Only Author and Title

Zawadzki T, Davies E, Dziubinska H, Trebacz K (1991) Characteristics of action potentials in Helianthus annuus. Physiol Plant 83: 601604

Google Scholar: Author Only Title Only Author and Title 